\title{
A light-triggered antibacterial hydrogel containing recombinant growth factor for treatment of bacterial infections and improved wound healing
}

Jiameng Wang a, Yanan $\mathrm{Li}^{\text {a }}$, Xiang Han ${ }^{\text {a }}$, Hongyu Zhang ${ }^{\mathrm{b}}$, Ailan Fan * a, Xiaohong Yao a , Bin Tang a, Xiangyu Zhang*a

${ }^{a}$ Laboratory of Biomaterial Surfaces \& Interfaces, Institute of New Carbon Materials, Taiyuan University of Technology, Taiyuan 030024, China

${ }^{\mathrm{b}}$ Second Hospital of Shanxi Medical University, Taiyuan 030024, China 

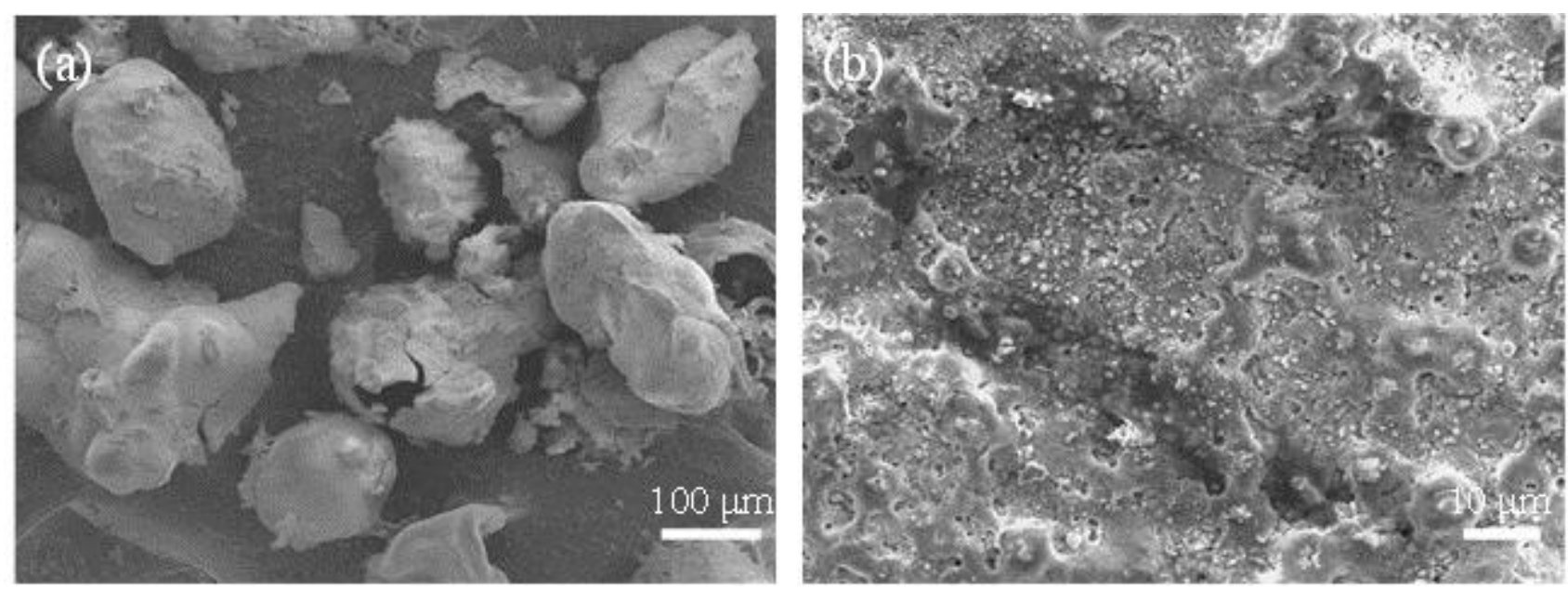

Figure S1. (a) SEM image of RB microspheres; (b) SEM image of PPy microspheres. 
(a)

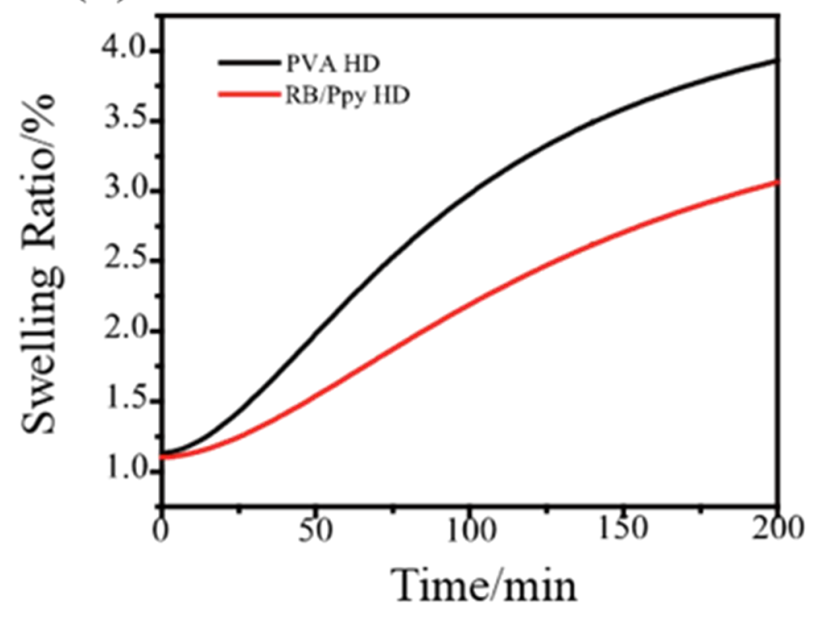

(b)

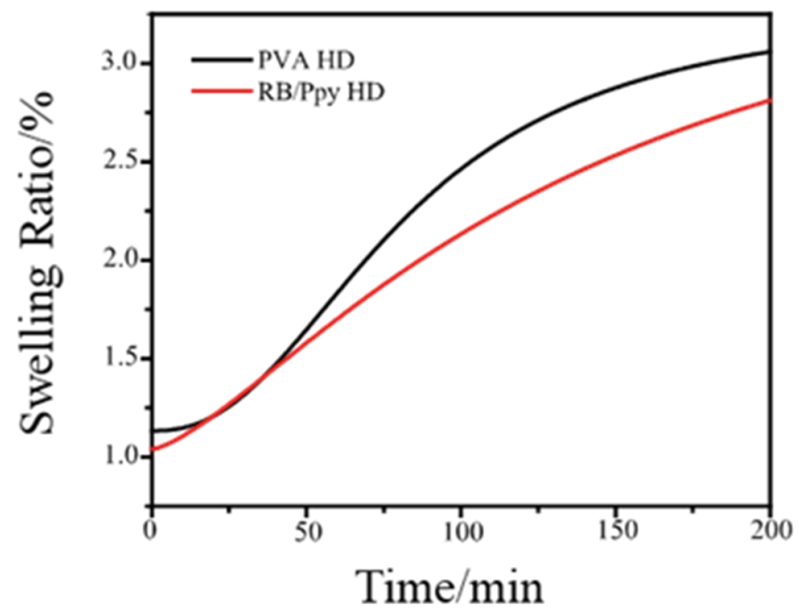

Figure S2. The swelling ratio of the RB/PPy PVA HD at $25^{\circ} \mathrm{C}$ (a) and $37^{\circ} \mathrm{C}$ (b). 
(a)

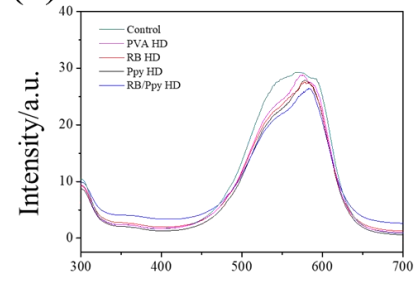

(e)

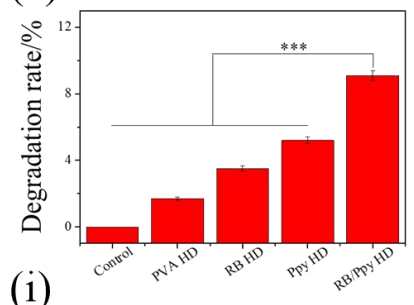

(i)

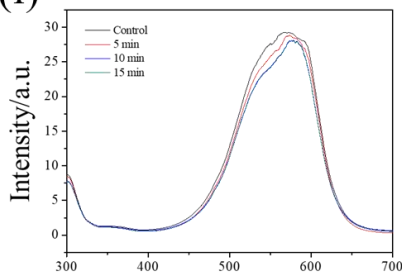

(m)

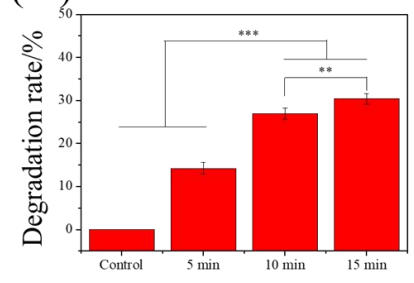

(b)

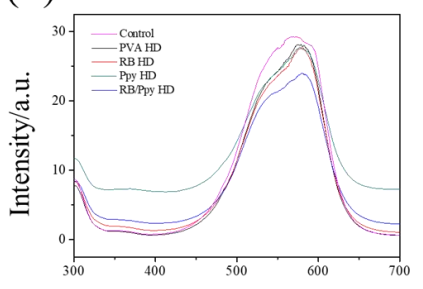

(f)

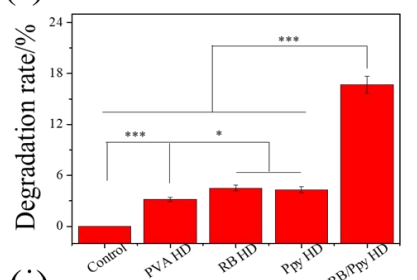

(j)

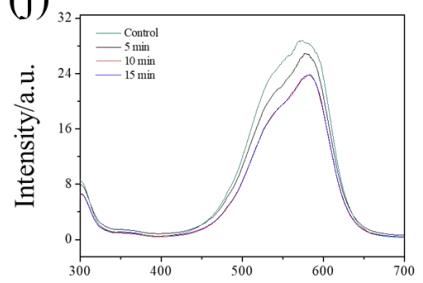

(n)

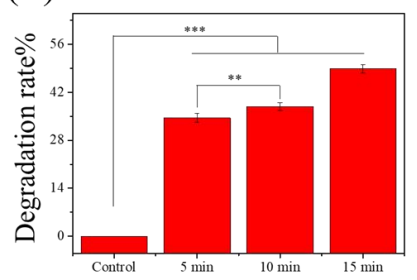

(c)

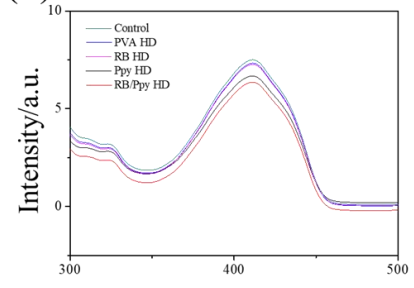

(g)

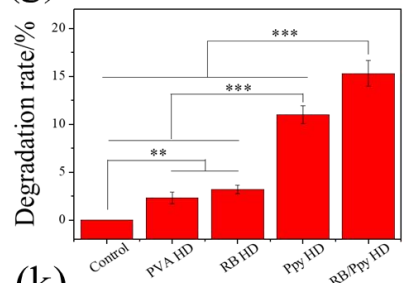

(k)

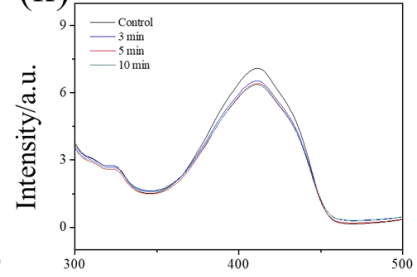

(o)

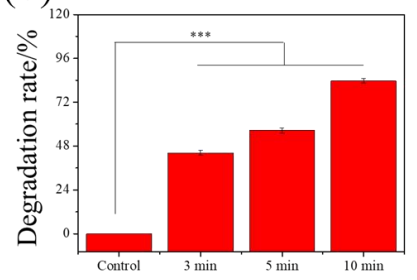

(d)

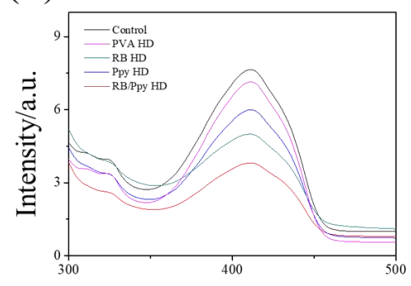

(h)

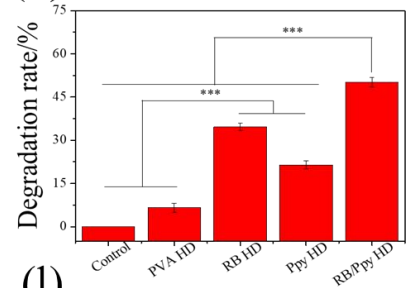

(1)

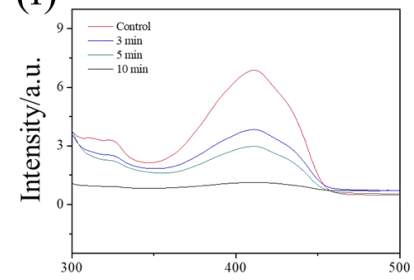

(p)

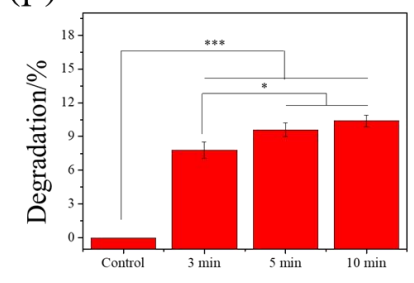

Figure S3. $\cdot$ OH detected from the degradation of MV of different samples at $808 \mathrm{~nm}$ NIR (a) and $550 \mathrm{~nm}$ VL (b) irradiation; ${ }^{1} \mathrm{O}_{2}$ detected from the degradation of DPBF of different samples at $808 \mathrm{~nm}$ NIR (c) and $550 \mathrm{~nm}$ VL (d) irradiation; The degradation efficiency of MV of different samples at $808 \mathrm{~nm}$ NIR (e) and $550 \mathrm{~nm}$ VL (f) irradiation; The degradation efficiency of DPBF of different samples at $808 \mathrm{~nm} \mathrm{NIR} \mathrm{(g)} \mathrm{and} 550 \mathrm{~nm} \mathrm{VL} \mathrm{(h)} \mathrm{irradiation;} \cdot \mathrm{OH}$ detected from the degradation of MV of RB/PPy PVA HD at $808 \mathrm{~nm}$ NIR (i) and $550 \mathrm{~nm} \mathrm{VL} \mathrm{(j)} \mathrm{irradiation} \mathrm{for}$ different times; ${ }^{1} \mathrm{O}_{2}$ detected from the degradation of DPBF of RB/PPy PVA HD at $808 \mathrm{~nm}$ NIR (k) and $550 \mathrm{~nm}$ VL (1) irradiation for different times; The degradation efficiency of MV of RB/PPy PVA HD at $808 \mathrm{~nm}$ NIR (m) and $550 \mathrm{~nm}$ VL (n) irradiation for different times; The degradation efficiency of DPBF of RB/PPy PVA HD at $808 \mathrm{~nm}$ NIR (o) and $550 \mathrm{~nm} \mathrm{VL} \mathrm{(p)} \mathrm{irradiation} \mathrm{for} \mathrm{different} \mathrm{times}\left({ }^{*} \mathrm{p}<0.05,{ }^{* *} \mathrm{p}<0.01,{ }^{* *} \mathrm{p}<0.001\right)$. 
(a) S.aureus

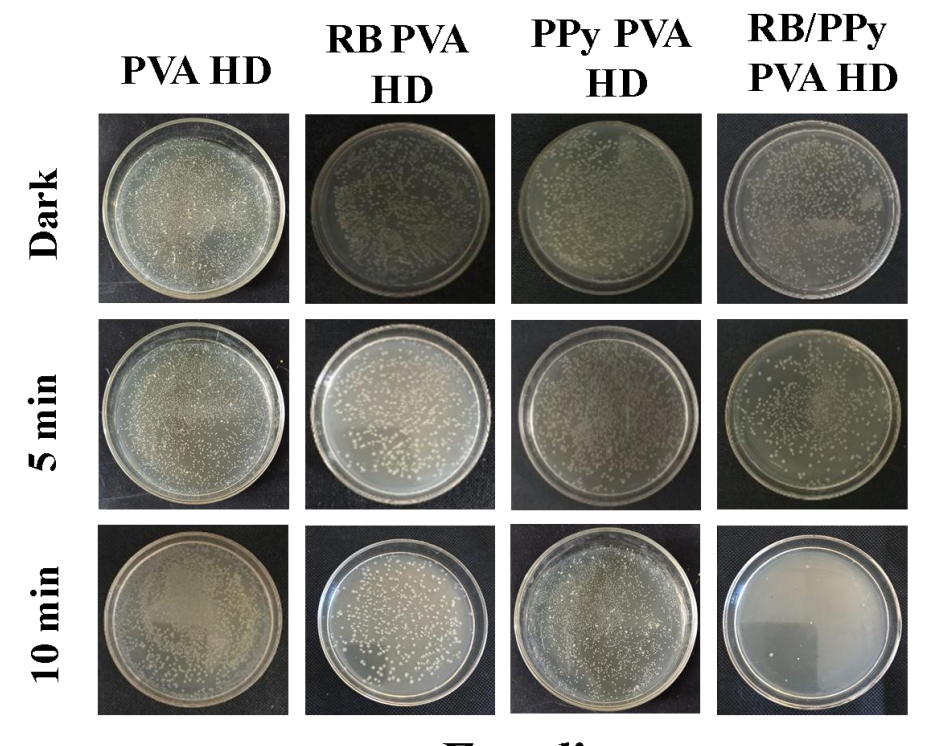

(b)

$$
\text { E. coli }
$$

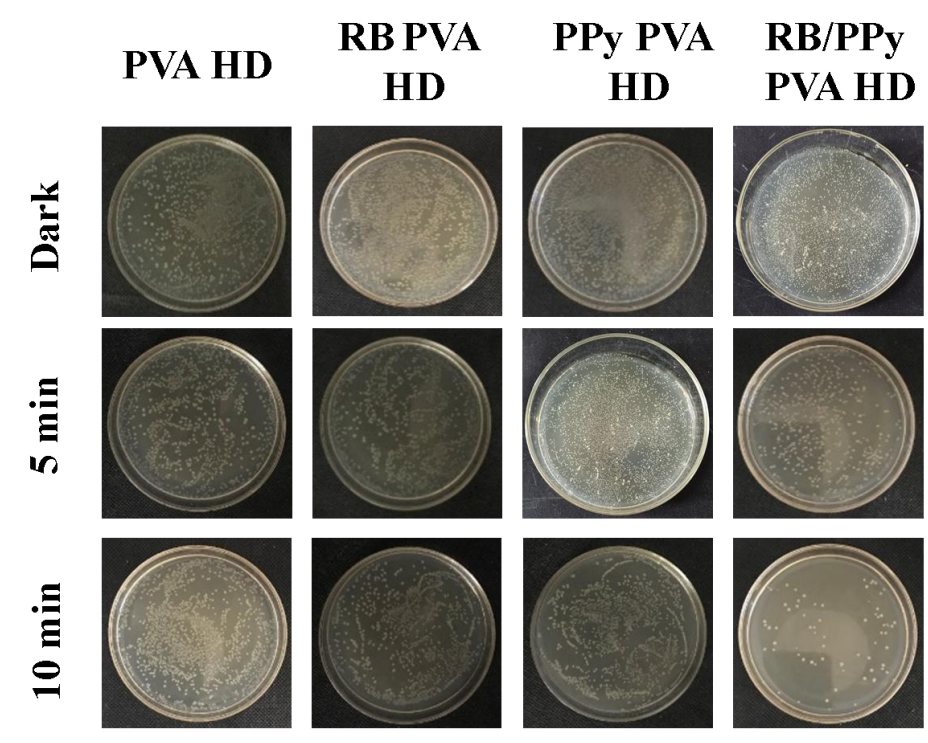

Figure S4. Photographs of bacterial colonies at $45^{\circ} \mathrm{C}$ for 5 and 10 min under dual light irradiation. 


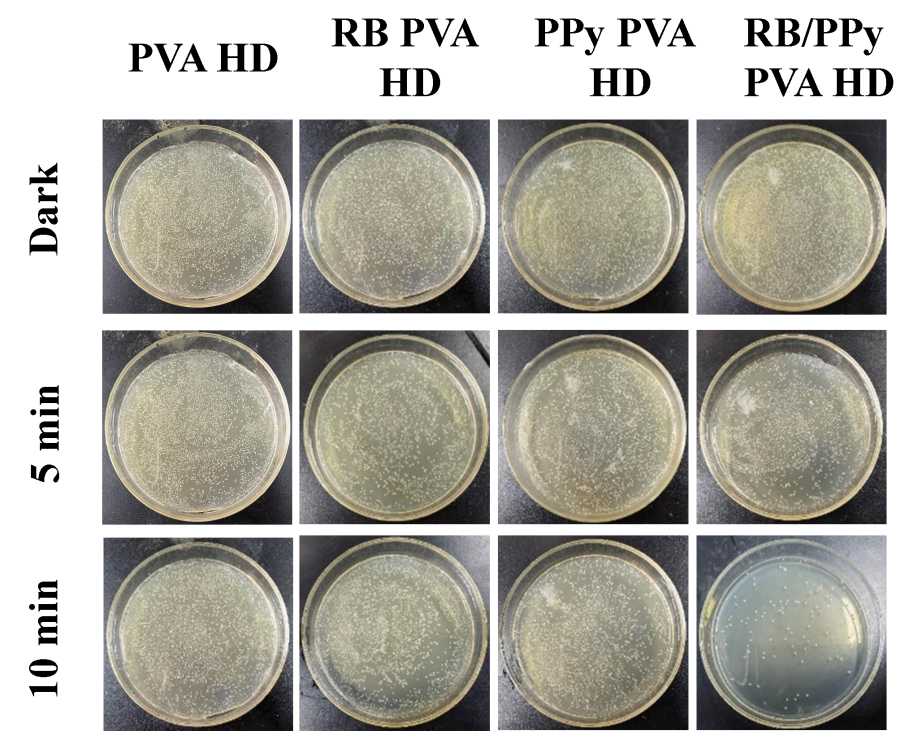

Figure S5. Photographs of bacterial colonies of MRSA at $45^{\circ} \mathrm{C}$ for 5 and 10 min under dual light irradiation. 